\title{
Editorial
}

\section{Corneal Collagen Cross Linking - PLUS}

The management of keratoconus and post - LASIK ectasia included until recently spectacle correction, Hard - Fitted Gas Permeable Contact Lenses, Intrastromal Corneal Ring Segments. All these interventions are purely symptomatic and their only aim is the improvement of visual function of patients, without interfering with the pathophysiology of the ectatic disorders. The only actual treatment for these entities, was either Lammelar or Penetrating Keratoplasty, especially in advanced cases. Even though, corneal keratoplasty offers the only treatment approach it demonstrates several disadvantages, such as slow visual rehabilitation and graft rejection, issues which interfere with patients quality of life both in the short and long term after surgery.

Corneal collagen cross linking (CXL) with the use of riboflavin and ultraviolet - A irradiation is a new innovative technique that can increase corneal resistance and rigidity (stiffening effect) [1,2]. This minimally invasive procedure can actually stabilize corneas with keratoconus or post - LASIK ectasia $[3,4]$ delaying or in some cases even avoiding the need for keratoplasty. It actually modifies corneal stromal structures and increases corneal strength and rigidity by inducing collagen cross - links in the corneal stroma.

The main advantage and at the same time the goal of CXL is to inhibit the progression of the ectatic disease and to increase the biomechanical rigidity of the cornea. The stiffening effect produced causes a postoperative reduction of keratometry, changing the shape of the cornea. Even so, visual outcomes are remotely improved [5] and in some cases even after CXL patients cannot achieve a functional visual acuity.

In order to optimize the result of CXL, adjuvant therapies (such as INTACS or customized ablations) have been proposed to develop a technique which can treat keratoconic patients and offer them both stability and functional vision. Several studies have been published that combine CXL and refractive surgery $[6,7]$ targeting to both stabilization and reshaping of the corneal tissue for visual function improvement. These combined methods could improve patients visual outcomes in addition to corneal stabilization (that can be named CXL plus).

We are experiencing a major change in ophthalmic practice and we are providing our patients further solutions while improving their quality of life. This is certainly a new era in treating corneal ectatic disorders that changes drastically gold standard treatments (PKP) that were unquestionable for over half a century. CXL plus is probably the way to the future, a conflated method which might represent an actual cure for all kinds of ectatic disorders of the cornea.

\section{REFERENCES}

[1] Wollensak G, Spoerl E, Seiler T. Riboflavin/ultraviolet-A-inducedcollagen crosslinking for the treatment of keratoconus. Am J Ophthalmol 2003; 135: 620-7.

[2] Wollensak G, Spoerl E, Seiler T. Stress-strain measurements of human and porcine corneas after riboflavin-ultraviolet-A-induced cross-linking. J Cataract Refract Surg 2003; 29: 1780-5.

[3] Caporossi A, Baiocchi S, Mazzotta C, Traversi C, Caporossi T. Parasurgical therapy for keratoconus by riboflavin-ultraviolet type A rays induced cross-linking of corneal collagen: preliminary refractive results in an Italian study. J Cataract Refract Surg. 2006; 32(5): 837-45.

[4] Hafezi F, Kanellopoulos J, Wiltfang R, Seiler T. Corneal collagen crosslinking with riboflavin and ultraviolet A to treat induced keratectasia after laser in situ keratomileusis. J Cataract Refract Surg 2007; 33(12): 2035-40.

[5] Raiskup-Wolf F, Hoyer A, Spoerl E et al. Collagen crosslinking with riboflavin and ultraviolet-A light in keratoconus: long-term results. J Cataract Refract Surg 2008; 34: 796-801.

[6] Kanellopoulos AJ, Binder PS. Collagen cross-linking (CCL) with sequential topography-guided PRK: a temporizing alternative for keratoconus to penetrating keratoplasty. Cornea 2007; 26: 891-5.

[7] Kymionis GD, Kontadakis GA, Kounis GA, et al. Simultaneous topography-guided PRK followed by corneal collagen cross-linking for keratoconus. J Refract Surg 2009; 25(9): S807-11.

George D. Kymionis

(Guest Editor)

Institute of Vision \& Optics

Department of Medicine

University of Crete

Heraklion, Crete

Greece

E-mail: kymionis@med.uoc.gr

(C) George D. Kymionis; Licensee Bentham Open.

This is an open access article licensed under the terms of the Creative Commons Attribution Non-Commercial License (http: //creativecommons.org/licenses/by$\mathrm{nc} / 3.0 /$ ) which permits unrestricted, non-commercial use, distribution and reproduction in any medium, provided the work is properly cited. 